\title{
Crónica Parlamentaria
}

\section{La organización territorial de la Comunidad Autónoma en el Estatuto de Autonomía}

Que los actuales Estatutos de Autonomía adolecen de una notable falta de profundización en la regulación de esta materia, es cosa bien conocida que no precisa mayor aclaración. Que, además, aun siendo parca, esa regulación, lisa y llanamente, no se ha aplicado jamás en algún extremo, convirtiéndose el Estatuto en letra muerta en tal aspecto, es asimismo una realidad bien conocida en nuestra Comunidad Autónoma, por cuanto el art. 4.4 del Estatuto contempló, en vano, la posibilidad de que las Diputaciones provinciales se encargasen de la gestión de los servicios periféricos de la Comunidad Autónoma. Consiguientemente, más allá del incremento de los ámbitos competenciales propios de la Comunidad Autónoma y de la renovación de los preceptos basilares en punto a la financiación, resultaba más que probable que los procesos de reforma estatutaria tendrían en la regulación de la organización territorial un amplio terreno donde desplegarse.

Sin embargo, la experiencia desarrollada hasta la fecha arroja un resultado dispar, pues, frente a las hondas transformaciones que en la materia introduce la propuesta de Estatuto de Cataluña, por el contrario, el estatuyente valenciano se ha mostrado mucho más contenido; mientras que, por el momento, la Proposición de Reforma del Estatuto de Autonomía para Andalucía ${ }^{1}$ puede situarse en una posición equidistante de los dos anteriormente mencionados. El reforzamiento de la materia se plasma gráficamente en el establecimiento de un Título específico, el III, que se encomienda expresamente a la "Organización Territorial de la Comunidad Autónoma". Pero, de otro lado, y en contraste, la nueva versión estatutaria conserva algunos aspectos del Estatuto de 1981 que, ciertamente, no parecen acomodarse al nivel cualitativo que han alcanzado los mecanismos garantizadores de la autonomía local tanto en la esfera internacional (véase la Carta Europea de la Autonomía Local), como en el Derecho Comparado y -lo que es sin duda más importante- en la propia jurisprudencia constitucional. Pero sobre esto tendremos que volver

\footnotetext{
${ }^{1}$ BOPA núm. 374, de 9 de febrero de 2006, pág. 21.054 y ss.
} 
necesariamente líneas abajo. Ahora lo que conviene es destacar que el estatuyente andaluz -a diferencia de la posición sostenida por el Parlamento catalán- ha rehuido la tesis según la cual es constitucionalmente factible la "interiorización plena" del régimen local en los Estatutos de Autonomía, con la subsiguiente postergación de la legislación básica del Estado en la correspondiente Comunidad Autónoma ${ }^{2}$. Ésta -decía- es una pretendida lectura del art. 149.1.18 CE que, con toda evidencia, no ha hecho suya el Parlamento andaluz, toda vez que reiteradamente la Proposición de Reforma del Estatuto de Autonomía para Andalucía recuerda la sujeción a la normativa básica estatal de las competencias que ostenta la Junta de Andalucía en relación con el régimen local. Así, el art. 56.1 establece sobre el particular: "En el marco de lo dispuesto en el Título III, la Comunidad Autónoma asume competencia exclusiva en materia de régimen local, sin perjuicio de lo que dispone el artículo 149.1.18 de la Constitución. Dicha competencia, respetando la normativa básica estatal y el principio de autonomía local incluye...". Mientras que, de otro lado, el art. 80.2 de la Proposición insiste expresamente en la aplicabilidad de la normativa estatal en la materia:

"La Administración de la Comunidad Autónoma y de las Administraciones locales ajustarán sus relaciones a los principios de información mutua, coordinación, colaboración y respeto a los ámbitos competenciales correspondientes determinados en el presente Estatuto, en la legislación básica del Estado y en la normativa autonómica de desarrollo".

Posiblemente uno de los ámbitos en donde se muestra más acusadamente las deficiencias de la propuesta estatutaria sea en la regulación de las provincias. En alguna ocasión, la previsión estatutaria roza la "inconstitucionalidad por omisión”, como cuando en el art. 80 -un artículo dedicado genéricamente a la estructura territorial- sólo se compromete el Estatuto a garantizar la autonomía municipal: "El Estatuto -se afirma en el apartado tercero del art. 80- garantiza a los municipios su núcleo competencial propio que será ejercido con plena autonomía con sujeción sólo a los controles de constitucionalidad y legalidad"3. El precepto ignora, pues, manifiestamente, que también las

\footnotetext{
2 Véase la -aunque no compartida- excelentemente articulada construcción doctrinal de Francisco Velasco Caballero "Organización territorial y régimen local en la reforma del Estatuto de Cataluña: límites constitucionales”, en Estudios sobre la reforma del Estatuto, Institu d'Estudis Autonòmics, Barcelona, 2004, pág. 283 y ss.
}

\footnotetext{
${ }^{3}$ Más atinadamente, el art. 56.1 de la Proposición subordina genéricamente al principio de autonomía local el ejercicio de la competencia autonómica sobre el régimen local.
} 
provincias ope Constitutionis disfrutan de la garantía de la automía local, y que ésta se traduce inesquivablemente en la existencia de un ámbito competencial propio provincial, que -como es obvio- también los Estatutos de Autonomía están llamados a garantizar. Así ha venido, por lo demás, a destacarlo recientemente el Libro Blanco para la Reforma del Gobierno Local ${ }^{4}$, según el cual "el principio constitucional de autonomía supone el reconocimiento de que los municipios y provincias han de estar dotados necesariamente de un haz mínimo de competencias", exigiendo además dicho principio que tales competencias se asignen a título de competencias propias (STC 4/1981, FJ 3), en el bien entendido de que sólo puede considerarse competencia propia la que es desempeñada por su titular bajo un régimen de autorresponsabilidad (STC 109/1998, FJ 13). En resumidas cuentas, la garantía de la autonomía local ex artículo 137 CE "se proyecta en la exigencia de que el legislador ha de atenerse a un mínimo competencial, que, como competencias propias, ha de reconocerse al ente local" (STC $109 / 1998$, FJ 13).

No resulta, pues, por las razones aludidas, muy acertada la redacción del art. 80.3 de la Proposición. Y si bien es cierto que esta disposición refleja la misma prevención que muestra el actual Estatuto a la hora de reconocer la autonomía provincial, no cabe soslayar que entre ambos textos median casi veinticinco años de jurisprudencia constitucional, en la que se ha reforzado sin ambages la naturaleza de las provincias como entes territoriales autónomos que, además, han de estar dotadas por imperativo constitucional de un haz mínimo de competencias propias. Por tanto, sea cual fuere el tenor literal del citado art. 80.3, el mismo ha de ser interpretado conforme a la Constitución y, en consecuencia, ha de entenderse que el Estatuto debe garantizar también a las provincias un núcleo competencial propio que pueda ser ejercido por éstas con plena autonomía.

Pero esto es precisamente lo que falla, desde el punto de vista constitucional, en el texto de la Proposición de Reforma: Asume respecto de la provincia una posición pareja a la sostenida en el año 1981, momento en el que no sólo se desconocía el alcance de la garantía constitucional de la autonomía provincial, dada la falta de jurisprudencia constitucional al respecto, sino que tampoco se podía vislumbrar que el Estado español se iba a comprometer con

\footnotetext{
${ }^{4}$ Ministerio de Administraciones Públicas. Secretaría de Estado de Cooperación Territorial, Madrid, 2005.
} 
un texto tan respetuoso con el nivel local de gobierno como lo es, sin duda, la Carta Europea de la Autonomía Local ${ }^{5}$. Es cierto que la penetración efectiva de la Carta en la praxis jurisprudencial española se ha producido de forma lenta y difícil, pero puede afirmarse que ya a fines de la década de los noventa parecían plenamente arraigadas las dos fundamentales manifestaciones en que viene a concretarse la virtualidad jurídica de dicho texto normativo: la de servir de auxilio al intérprete a la hora de precisar la extensión de la autonomía local constitucionalmente protegida, y la de establecer un estándar mínimo de protección de las Entidades Locales al que necesariamente debe sujetarse la normativa infraconstitucional. Y en lo que concierne a esto último, no cabe soslayar que la Carta -al igual que la generalidad de los Tratados internacionales- tiene fuerza pasiva frente a las leyes, de tal modo que allá donde se identifique una contradicción entre aquélla y una norma legal tendrá que optarse necesariamente por lo establecido en la Carta. Y ésta es una decisión que ha de adoptar la jurisdicción ordinaria, puesto que las colisiones entre los Tratados y las leyes no encierran sino un problema de selección del Derecho aplicable, cuya "resolución corresponde a los órganos judiciales en los litigios de que conozcan" (STC 28/1991, FJ 5). De otra parte, como apuntamos, la Carta también presenta la virtualidad de operar como instrumento hermenéutico para determinar el alcance de la autonomía local constitucionalmente garantizada. Rechada por el Tribunal Constitucional la tesis más ambiciosa según la cual la Carta podría servir, per se, como parámetro de constitucionalidad de las leyes (STC 235/2000, FJ 11), lo que sí resulta irrebatible a estas alturas es que la misma puede resultar de utilidad para terminar de perfilar el alcance de la autonomía configurado por las normas integrantes del bloque de la constitucionalidad. Así se desprende, de una parte, de la más reciente jurisprudencia constitucional, que se cuida de invocar en este contexto los pertinentes preceptos de la Carta (así, por ejemplo, SSTC 235/2000, FJ 11 y 159/2001, FJ 4). Y así se infiere igualmente de la jurisprudencia del Tribunal Supremo, que ha asumido sin ambages dicha función hermenéutica (STS de 21 de mayo de 1997, Fundamento de Derecho Quinto). Se hace, pues, evidente que el alcance constitucional de la autonomía local ha de interpretarse a la luz de la Carta, debiendo por ende traerse a colación necesariamente por los operadores jurídicos cuando se planteen dudas acerca de la eventual vulneración de dicha autonomía. Se trata de una función hermenéutica tan in-

\footnotetext{
5 Sobre la necesaria acomodación del concepto constitucional de "autonomía local" a las exigencias de la Carta Europea de la Autonomía Local, véase sobre todo Francisco Caamaño Domínguez (coord.): La autonomía de los entes locales en positivo. La Carta Europea de la Autonomía Local como fundamento de la suficiencia financiera, Fundación Democracia y Gobierno Local, Madrid, 2003.
} 
controvertida que, incluso, en alguna ocasión el Tribunal Constitucional ha recurrido sin más a un precepto de la Carta para integrar el contenido de una determinada dimensión o vertiente de la autonomía local constitucionalmente consagrada (así, respecto de la autonomía tributaria local, STC 233/1999, FJ 11).

En resumidas cuentas, si en el contexto normativo y jurisprudencial del año 1981 era explicable una regulación como la que terminaría asumiendo el estatuyente respecto de las provincias, transcurrido casi un cuarto de siglo, su reiteración resulta un elemento extraño en un nuevo marco conceptual tanto más atento y sensible a las exigencias de la autonomía local. Pues, sencillamente, se habilita una amplísima facultad coordinadora de la Junta de Andalucía, susceptible incluso de proyectarse en el reducto donde se condensa el núcleo esencial de la autonomía provincial, a saber, la cooperación económica a los municipios. En efecto, el nuevo texto -siguiendo la estela, como decíamos, del vigente Estatuto- reafirma, e incluso amplía, las competencias de coordinación de la Comunidad Autónoma. El ámbito competencial provincial queda descrito, en el art. 87.3, en los siguientes términos:

“Serán competencias de la Diputación las siguientes:

La gestión de las funciones propias de la coordinación municipal, asesoramiento, asistencia y cooperación con los municipios, especialmente los de menor población que requieran de estos servicios, así como la posible prestación de algunos servicios supramunicipales, en los términos y supuestos que establezca la legislación de la Comunidad Autónoma.

Las que con carácter específico y para el fomento y la administración de los intereses peculiares de la provincia le vengan atribuidas por la legislación básica del Estado y por la legislación que dicte la Comunidad Autónoma en desarrollo de la misma.

Las que pueda delegarle para su ejercicio la Comunidad Autónoma, siempre bajo la dirección y el control de ésta".

Pues bien, como adelantamos, la Proposición de Reforma del Estatuto contempla una capacidad de interferencia genérica de la Junta de Andalucía en el ámbito de la cooperación con los municipios, que, como es sabido, constituye el "núcleo duro" definitorio de la autonomía provincial en el plano competencial. En efecto, el art. 87.4 establece al respecto: "La Junta de Andalucía coordinará la actuación de las Diputaciones, en lo que se refiere a las 
competencias recogidas en el número 3 del presente artículo, en materias de interés general para Andalucía. La apreciación del interés general y las fórmulas de coordinación se establecerán por una ley aprobada por mayoría absoluta del Parlamento de Andalucía y en el marco de lo que disponga la legislación básica del Estado. En todo caso, la Comunidad Autónoma coordinará los Planes Provinciales de Obras y Servicios".

No es preciso insistir en la relevancia que tendrá la futura Ley reguladora del Gobierno Local en la delimitación del alcance exacto de esta potestad coordinadora de la Comunidad Autónoma. Que el Estado, ope art. 149.1.18 CE, está habilitado para fijar el marco dentro del cual ha de desenvolverse la coordinación autonómica, es una afirmación ya reiterada en la jurisprudencia constitucional. Como se apuntó ya en la Sentencia LOAPA (STC 76/1983), "dentro de dicha competencia ha de entenderse comprendida la regulación de las relaciones entre las distintas Administraciones y, por ende, de las bases a que habrá de ajustarse la coordinación entre éstas, así como las transferencias o delegaciones de funciones administrativas a favor de las Diputaciones Provinciales" (FJ 18). Y así quedaría de inmediato corroborado en la práctica en la Sentencia de las Diputaciones valencianas (STC 27/1987), en donde el examen de la constitucionalidad de la Ley autonómica impugnada se realiza a través de un diálogo permanente entre la norma estatutaria y la norma básica estatal, de tal manera que sólo se admite la constitucionalidad de aquellas medidas coordinadoras que puedan considerarse compatibles con las previsiones de la Ley de Bases del Régimen Local. Tal sucede, por ejemplo, cuando se aborda la constitucionalidad de las "directrices" (FJ 6) o de los "reparos" en materia presupuestaria (FJ 8). Y, consecuentemente, se considera inconstitucional la suspensión aneja al requerimiento de ilegalidad por no poder entenderse bajo la cobertura de la Ley de Bases:

"Es de señalar, sin embargo, que la inmediata suspensión aneja al requerimiento de ilegalidad, que es lo que verdaderamente impugnan los recurrentes, no responde al sistema general de control de legalidad contenido en la mencionada Ley de Bases (arts. 65 y 66); la vigente legislación estatal no sólo no la ha previsto sino que, por contraposición a la normativa anterior (Ley 40/1981, de 28 de octubre, sobre el Régimen Jurídico de las Corporaciones Locales), ha pretendido excluir efectivamente la suspensión administrativa de los Acuerdos de las Administraciones locales sometidos a control de legalidad por otras Administraciones superiores (la del Estado y las de las Comunidades Autónomas), reservando a los Tribunales la decisión relativa a la suspensión o no de tales Acuerdos en caso de impugnación. Por otra parte, contra lo pretendido por la representación del Gobierno Valenciano, dicho efecto suspen- 
sivo no queda tampoco amparado por el art. 59.2 de la Ley de Bases de Régimen Local, que permite a las Asambleas Legislativas de las Comunidades $\mathrm{Au}-$ tónomas reservarse fórmulas adicionales de control en función de las potestades autonómicas de coordinación, pues el art. 12 impugnado no contempla un supuesto de control realizado por las Cortes Valencianas, sino directa y exclusivamente por el Gobierno de la Comunidad Autónoma" (FJ 9).

En definitiva, según afirmó el Magistrado Rubio Llorente en el voto particular formulado a la STC 27/1987 refiriéndose a la Ley de Bases, "el Tribunal, acertadamente, (la) ha utilizado como parámetro de la constitucionalidad puesto que es elemento esencial de la "legislación del Estado", en cuyo marco ha de ejercerse la facultad de coordinación que a la Comunidad Valenciana otorga el art. 47.3 de su Estatuto de Autonomía”.

No obstante, con independencia de las reglas que la futura Ley reguladora del Gobierno Local establezca para encauzar el ejercicio de las facultades coordinadoras de las CCAA, no puede dejar de recordarse que -en todo casola potestad de coordinación encuentra un límite constitucional inesquivable en la exigencia de respetar el principio de autonomía local. De entrada, ha de tenerse presente que "tal coordinación no supone, sin embargo, una sustracción o menoscabo de las competencias de las entidades sometidas a la misma; antes bien, presupone lógicamente la titularidad de las competencias en favor de la entidad coordinada (...) Así entendida, la coordinación constituye un límite al pleno ejercicio de las competencias propias de las Corporaciones Locales y como tal, en cuanto que afecta al alcance de la autonomía local constitucionalmente garantizada, sólo puede producirse en los casos y con las condiciones previstas en la Ley" (STC 27/1987, FJ 2). En segundo término, la potestad coordinadora, "aunque sin alterar... la titularidad y el ejercicio de las competencias propias de los entes en relación”, entraña unos efectos y consecuencias más intensos que los propios de las técnicas estrictamente cooperativas: "La voluntariedad en el caso de la cooperación frente a la imposición en la coordinación -ya que toda coordinación conlleva un cierto poder de dirección, consecuencia de la posición de superioridad en que se encuentra el que coordina respecto al coordinado- es, por sí mismo, un elemento diferenciador de primer orden, lo que explica y justifica que, desde la perspectiva competencial, distintas hayan de ser las posibilidades de poner en práctica unas y otras fórmulas" (STC 214/1989, FJ 20 A f). Así, pues, a diferencia de las fórmulas o instrumentos de cooperación, la coordinación "implica un límite efectivo al ejercicio de las competencias (entre otras SSTC 32/1983, fundamento jurídico 2; 80/1985, fundamento jurídico 2, y 27/1987, fundamento jurídico 5)" (STC 214/1989, FJ 20 A f). 
Ahora bien, esa capacidad "limitadora" del ejercicio de las competencias ajenas inherente a la potestad de coordinación tampoco puede concebirse en términos ilimitados o incondicionados. Pues, en efecto, al socaire de la coordinación, no cabe articular medidas que puedan "suponer una modalidad de control ni colocar a las Diputaciones Provinciales en una posición de subordinación jerárquica o cuasi jerárquica incompatible con la autonomía”; y, así, de hecho, la coordinación "no puede traducirse en la emanación de órdenes concretas que prefiguren exhaustivamente el contenido de la actividad del ente coordinado, agotando su propio ámbito de decisión autónoma; en cualquier caso, los medios y técnicas de coordinación deben respetar un margen de libre decisión o de discrecionalidad en favor de las Administraciones sujetas a la misma, sin la cual no puede existir verdadera autonomía" (STC 27/1987, FJ 6). Así, pues, ha de entenderse que excede con creces la posibilidad de emplear legítimamente la potestad coordinadora cuando con la misma se pretende la instauración de controles de oportunidad; esto es, controles que "responden a criterios de oportunidad política que interfieran en el libre ámbito de responsabilidad político-administrativa de las Diputaciones Provinciales" (STC 27/1987, FJ 8).

Las directrices jurisprudenciales recién referidas deben necesariamente tomarse en consideración siempre que se discuta la adecuación al bloque de la constitucionalidad de las medidas autonómicas destinadas a la coordinación provincial. Así vino a sintetizar dicho cúmulo de líneas, principios y pautas jurisprudenciales la STC 109/1998 en su fundamento jurídico decimotercero, al aplicarla precisamente a un conflicto trabado entre una Comunidad Autónoma y una Diputación Provincial:

"Esta lesión tampoco puede justificarse en el singular instrumento coordinador en que consiste el Plan Unico. Cierto es que, refiriéndonos precisamente a las relaciones interadministrativas de las Corporaciones Locales, ya hemos tenido ocasión de señalar que las facultades de coordinación -a diferencia de las técnicas de colaboración, basadas en la participación voluntaria y, por ende, en una situación más nivelada de los entes cooperantes- conllevan «un cierto poder de dirección, consecuencia de la posición de superioridad en que se encuentra el que coordina respecto al coordinado» [STC 214/1989, fundamento jurídico 20 f)]. Y siendo, consiguientemente, la imposición una de las principales notas distintivas de la coordinación frente a la voluntariedad que caracteriza a las fórmulas cooperativas [cfr., además, STC 331/1993, fundamento jurídico 5. A) ], es claro que el que ostenta atribuciones de aquella índole está legitimado, en línea de principio, para establecer unilateralmente 
medidas armonizadoras destinadas a la más eficaz concertación de la actuación de todos los entes involucrados. Desde esta perspectiva, puede en verdad afirmarse que la coordinación «constituye un límite al pleno ejercicio de las competencias propias de las Corporaciones Locales» [STC 27/1987, fundamento jurídico 2.; asimismo STC 214/1989, fundamento jurídico $20 \mathrm{f}$ )]. Ahora bien, las posibilidades que la coordinación proporciona de operar de modo constitucionalmente válido llegan justamente hasta aquí. Más allá de este punto, encuentran el obstáculo constitucional infranqueable en que se sustancia la garantía institucional de la autonomía local: «la coordinación -precisamos en la STC 27/1987no entraña la sustracción de competencias propias de las entidades coordinadas, sino que implica tan sólo un límite al ejercicio de las mismas» (fundamento jurídico 5.). De donde resulta que la misma no puede, bajo ningún concepto, «traducirse en la emanación de órdenes concretas que prefiguren exhaustivamente el contenido de la actividad del ente coordinado, agotando su propio ámbito de decisión autónoma; en cualquier caso, los medios y técnicas de coordinación deben respetar un margen de libre decisión o de discrecionalidad en favor de las Administraciones sujetas a la misma, sin la cual no puede existir verdadera autonomía» (fundamento jurídico 6.)".

La posición sostenida por la Proposición de Reforma del Estatuto en punto a las provincias -que, al igual que la redacción vigente, sujeta a las mismas a un intenso control de la Comunidad Autónoma, vía facultades de coordinación- sólo ha sido objeto de una cierta matización por parte del Grupo Parlamentario Popular. En primer término, este grupo persigue que la dependencia de las provincias a la Junta de Andalucía no se recoja en términos tan categóricos, y a tal objeto defiende una enmienda al art. 87.3 a) destinada a garantizar que las diputaciones andaluzas gocen de las atribuciones de coordinación municipal y la competencia para prestar algunos servicios municipales que le permita la normativa estatal. En efecto, sugiere sustituir el inciso final "en los términos y supuestos que establezca la legislación de la Comunidad Autónoma" por el siguiente: "en los términos y supuestos que establezca la legislación aplicable". Y, en segundo lugar, el Grupo Parlamentario Popular persigue aligerar la capacidad de interferencia de la Junta de Andalucía, vía facultades de coordinación, solicitando la supresión del último inciso que faculta expresamente a la Junta de Andalucía a coordinar los Planes Provinciales de Obras y Servicios.

No obstante, aun siendo tremendamente incisiva y penetrante la capacidad coordinadora que la Propuesta de reforma atribuye a la Comunidad Au- 
tónoma, no le resulta bastante a los Grupos Parlamentarios Izquierda Unida y Andalucista, que abiertamente propugnan la práctica sustitución de las provincias por las comarcas. Y no es que la Proposición de Reforma desconozca o ignore por completo a la "comarca", pero -manteniendo la línea del texto actual- posterga su constitución al momento post-estatuyente: "Por Ley del Parlamento andaluz podrá regularse la creación de comarcas, atendiendo a sus características geográficas, económicas, sociales e históricas. Se requerirá en todo caso el acuerdo de los Ayuntamientos afectados y la aprobación del Consejo de Gobierno". En contraste con esta posición más cautelosa, el Grupo Parlamentario Andalucista defiende "que las Provincias y las Diputaciones deben quedar reducidas al mínimo constitucional. Por tanto, la transferencia de competencias ha de hacerse a las comarcas y, en su caso, a los municipios, reservándose en todo caso la Comunidad Autónoma la potestad normativa”. Una singular perplejidad produce la posición sostenida por el Grupo Parlamentario Izquierda Unida-Los Verdes, ya que algunas de sus propuestas colisionan de un modo patente con el ordenamiento constitucional. $\mathrm{O}$ bien esto es fruto de un absoluto desconocimiento de la jurisprudencia constitucional ya plenamente consolidada, o bien no es sino expresión de su voluntad de situarse al margen del marco constitucional. Tertium non datur. Baste señalar algunos ejemplos:

Por una parte, el Grupo Parlamentario Izquierda Unida pretende sustituir a las provincias en cuanto entidad local, tal y como se desprende en de la redacción alternativa que propone al párrafo primero del art. 80 de la Proposición de reforma estatutaria: "Andalucía se estructura territorialmente en municipios y comarcas, sin perjuicio de la existencia de las provincias esencialmente como división territorial para el cumplimiento de las actividades del Estado". Pese a la calculada ambigüedad del adverbio "esencialmente", es claro que el tenor literal del precepto implica prácticamente la supresión de la provincia de la estructura territorial de Andalucía, con el subsiguientemente quebrantamiento de la estructura territorial diseñada en el Título VIII de la Constitución, que contempla a la provincia como una entidad dotada de autonomía. Así se desprende, por lo demás, de la concepción que defiende en punto a las competencias de las comarcas, que claramente vendrían a usurpar el tradicional ámbito competencial propio provincial: "La comarca -apunta la propuesta de Izquierda Unida- es el ámbito territorial específico del gobierno intermunicipal y de cooperación local. Le corresponde la gestión de competencias y servicios intermunicipales, y de los que les encomienden los respectivos ayuntamientos o delegue la Comunidad Autónoma”. Naturalmente, el práctico vaciamiento competencial de las provincias -que sólo se mantendrían como un simple nombre- es una eventualidad vetada por el texto consti- 
tucional, como el Tribunal Constitucional tuvo ya ocasión de señalar en una de sus primeras decisiones a propósito de las Diputaciones catalanas. Quizás no haya pretendido este grupo parlamentario sino seguir la estela de la Propuesta de Estatuto de Cataluña, en la que la organización territorial de la Generalidad pasa a articularse en torno a las veguerías. Pero, de ser así, se ha seguido dicho precedente de forma errónea: la veguería vendría a sustituir a las Diputaciones, que, en cuanto órganos de gobierno de las provincias, sí son sustituibles como se deduce del art. 141.2 CE: "El gobierno y la administración autónoma de las provincias estarán encomendados a Diputaciones u otras Corporaciones de carácter representativo". Ahora bien, es el actual órgano de gobierno de la provincia -la Diputación-, pero no aquélla en cuanto ente local constitucionalmente protegido, el que puede ser objeto de supresión.

De otro lado, el Grupo Parlamentario Izquierda Unida Los Verdes pretende extender a las comarcas la garantía constitucional de la autonomía local: "Se garantiza la autonomía política y administrativa de municipios y comarcas, de acuerdo con lo establecido en la Constitución, el Estatuto y la Carta Europea de la Autonomía Local". Pero, obviamente, esta sugerencia ignora que el alcance y sentido de las garantías constitucionales no está a disposición de la normativa infraconstitucional; ni siquiera, claro está, del estatuyente. Y, como es sabido, la garantía constitucional de la autonomía local sólo se proyecta a los entes locales constitucionalmente necesarios, esto es, municipios y provincias, resultando las restantes entidades locales que puedan constituirse "entes de creación legal”, que, en consecuencia, no reciben más protección jurídica que la que pueda brindarle la normativa infraconstitucional.

Dicho lo anterior, no puede dejar de señalarse que el Grupo Parlamentario Izquierda Unida aporta también algunas propuestas valiosas. Como tal debe calificarse, ciertamente, la pretensión de consolidar en el Estatuto de Autonomía una esfera competencial propia de los municipios, avanzando así en una línea iniciada por el estatuyente catalán. A este respecto sugiere que los municipios tengan "en todo caso" competencias propias en una amplia gama de ámbitos materiales (urbanismo, vivienda, servicios sociales, educación infantil, seguridad, patrimonio histórico, etc.). Se trataría -de aceptarse- de un sustancial avance respecto de lo previsto en la Proposición de reforma, ya que se consolidaría en el Estatuto de Autonomía un listado de concretos ámbitos materiales en donde sería inesquivable la presencia -con capacidad decisoriadel gobierno local. Listado que, obviamente, dista mucho de estar asegurado en la Proposición, puesto que, de una parte, se limita a reconocer una cláusula genérica a favor de los municipios: "Corresponde al municipio la gestión de todos los asuntos que sean de interés local, siempre que no se trate de una 
competencia exclusiva atribuida a otra Administración o estuviera expresamente excluida de la competencia local, en el ámbito de la legislación de la Comunidad Autónoma" (82.2). Y, de otra parte, se ciñe a regular-de una forma harto discutible, como se verá- la delegación y transferencia de competencias en los Ayuntamientos: "Por ley, aprobada por mayoría absoluta, se podrá proceder a la delegación y transferencia de competencias en los Ayuntamientos siempre con la necesaria suficiencia financiera para poder desarrollarla y de acuerdo con los principios de legalidad, responsabilidad, transparencia, coordinación y lealtad institucional, quedando en el ámbito de la Junta de Andalucía la planificación y control de las mismas". Reserva en manos de la Comunidad Autónoma de la planificación y control que, como es palmario, no puede proyectarse a los supuestos de transferencia competencial, ya que la transferencia -a diferencia de la delegación- entraña que las competencias pasan a ser "competencias propias" del ente que las recibe, pasando a ejercerlas bajo su propia responsabilidad; circunstancia ésta claramente incompatible con el mantenimiento de su planificación y control por parte del ente que las transfiere.

Igualmente positiva es la propuesta del Grupo parlamentario Izquierda Unida-Los Verdes de incorporar un precepto en el que se refuerce la potestad de autoorganización municipal; una potestad que integra el núcleo duro de la autonomía local que, por lo demás, fue objeto de una intensa regulación en la última reforma de la Ley de Bases del Régimen Local: "Los municipios disponen de plena capacidad de autoorganización dentro del marco de las disposiciones generales establecidas por la ley en materia de organización y funcionamiento municipal".

El examen -siquiera somero- de la Proposición de reforma del Estatuto de Autonomía revela que el estatuyente no ha avanzado excesivamente en el fortalecimiento del nivel local de gobierno en lo que a las provincias concierne. Valoración que se pone asimismo de manifiesto respecto de lo que puede ciertamente considerarse un paso adelante de la Proposición respecto del vigente texto estatutario, a saber, la previsión de constituir un órgano mixto Comunidad Autonomía/Administración Local. En efecto, de acuerdo con el art. 86 de la Proposición: "Una ley de la Comunidad Autónoma regulará la creación, composición y funciones de un órgano mixto con representación de la Junta de Andalucía y de los Ayuntamientos andaluces, que informará preceptivamente las disposiciones normativas que afecten de forma específica a las Corporaciones locales. Dicho órgano, de carácter bilateral, funcionará como foro permanente de diálogo y colaboración institucional". Como es palmario, se echa en falta en el precepto una referencia expresa a los órganos de go- 
bierno de las provincias, que, consecuentemente, carecerán de una representación directa en ese nuevo "órgano mixto de la Junta de Andalucía y los Ayuntamientos". Ausencia injustificable que, por lo demás, tampoco queda subsanada en la redacción alternativa que el Grupo Parlamentario Popular ha propuesto respecto del citado art. 87; deficiencia que resulta tanto más llamativa cuanto que el texto alternativo presentado apunta a una notable apuntalamiento del papel del gobierno local. Así es; dicho Grupo Parlamentario defiende, de una parte, que "en el procedimiento de elaboración de las leyes y disposiciones reglamentarias de la Comunidad Autónoma" se tenga "en cuenta el impacto municipal del contenido de las mismas", así como que los ayuntamientos andaluces participen "en la planificación de las inversiones de la Junta de Andalucía en sus respectivos términos municipales". Y, de otro lado, apunta la conveniencia de incluir un precepto del siguiente tenor: "Corresponde a los plenos de las Corporaciones la adscripción y el control de los medios de comunicación públicos locales y la elección de sus directores".

Manuel Medina Guerrero 